\title{
GÊNERO E PROFISSÕES CIENTÍFICAS E TECNOLÓGICAS NO BRASIL
}

\author{
GENDER AND SCIENTIFIC AND TECHNOLOGICAL \\ PROFESSIONS IN BRAZIL
}

Nanci Stancki da Luz

\begin{abstract}
Resumo
Este trabalho tem como objetivo refletir sobre a divisão sexual do trabalho no Brasil, analisando particularmente as carreiras científicas e tecnológicas que historicamente tiveram predominância masculina no que se refere à composição de gênero de seus profissionais. Tal discussão é feita a partir da Relação Anual de Informações Sociais - RAIS² - do Ministério do Trabalho e Emprego, destacando algumas profissões tradicionalmente associadas ao campo científico e tecnológico, tais como Matemático(a), Estatístico(a), Físico(a), Químico(a), Engenheiro(a) e Professor(a) de Ensino Superior. Essa análise levará em consideração dados sobre o emprego formal dos anos de 2001 e 2006, e as variáveis, sexo, faixa etária e renda média. Tais dados apontam para a manutenção da baixa participação feminina nas profissões analisadas e a manutenção de desigualdades de gênero, expressas principalmente em diferenças salariais.
\end{abstract}

Palavras-chave: gênero, profissões científicas e tecnológicas, divisão sexual do trabalho

\begin{abstract}
This paper aims at reflecting about the sexual division of labor in Brazil, analyzing particularly scientific and technological professions that historically were predominantly masculine as per the gender composition of those professionals. Such discussion was established departing from the Annual Social Bits of Information - RAIS ${ }^{3}$ of the Employment and Labor Ministry, emphasizing some professions traditionally associated to the scientific and technological fields, such as Mathematics, Statistics, Physics, Chemistry, Engineering and Professors of Upper Schools (Universities). This analysis will take in consideration some data on formal employment in 2001 and 2006 , and the variables, such as sex, age and average income. Such data point out to the maintenance of very low female participation in the analyzed professions and the maintenance of gender inequalities, expressed mainly in wage differences.
\end{abstract}

Key words: gender, scientific and technological professions, labor gender division

1 Doutora em Política Científica e Tecnológica (UNICAMP); professora do Programa de Pós-Graduação em Tecnologia e do Departamento Acadêmico de Matemática da Universidade Tecnológica Federal do Paraná - Brasil; pesquisadora do Grupo de Estudos e Pesquisas sobre Relações de Gênero e Tecnologia - GeTec; e-mail: nancist@terra.com.br.

2 Doctor in Scientific and Technological Politics (UNICAMP); professor of Post-Graduation Program in Technology and of the Academic Department of Mathematics of the Technological Federal University of Paraná - Brazil; researcher of Study Groups on Gender Relations and Technology - GeTec; email:nancist@terra.com.br

RAIS é um Registro Administrativo, de periodicidade anual, criada com objetivo de suprir necessidades de controle, de estatísticas e de informações sobre o mercado formal de trabalho.

3 RAIS is and Administrative Register, issued annually, created with the aim of furnishing control needs, statistics and some information on the formal labor market. 


\section{INTRODUÇÃO}

A participação feminina no mercado de trabalho brasileiro vem sendo ampliada nas últimas décadas, todavia desigualdades de gênero permanecem marcando a presença das mulheres em diversas profissões. As mulheres ainda enfrentam processos de segregação caracterizados por discriminação, precarização do trabalho e desvalorização profissional.

A divisão sexual do trabalho separa e hierarquiza as atividades laborais. Historicamente atribuiu-se às mulheres as tarefas do âmbito privado (cuidado com filhos, trabalho doméstico, etc) e, aos homens, as tarefas do espaço público (produção de bens de consumo, atividades políticas, etc). $\mathrm{O}$ trabalho feminino, em grande medida, foi menos valorizado socialmente e associado ao cuidado, afetividade, paciência e destreza manual. Por outro lado, atividades realizadas por homens foram associadas a atributos tais como força física e razão.

Nesse universo - da racionalidade - supostamente masculino, estão inseridas as profissões científicas e tecnológicas, seja porque a ciência e a tecnologia foram campos de conhecimento desenvolvidos a partir de uma participação majoritária de homens, seja porque houve invisibilidade das atividades femininas nessas áreas de conhecimento ou porque as atividades femininas não foram consideradas como parte dessa construção. A suposta contradição entre emoção e razão, a associação das mulheres ao âmbito privado, a aceitação da natureza emocional e sensível das mulheres, dentre outros fatores, contribuíram para o afastamento das mulheres dessas profissões consideradas durante muito tempo como mais adequadas ao masculino.

A ciência e a tecnologia foram construídas social e historicamente como espaços de atuação masculina, estruturando-se inicialmente a partir de princípios que se associavam a atributos considerados masculinos tais como racionalidade, objetividade e universalidade. Tal construção, certamente envolta em relações de poder entre homens e mulheres, favoreceu para que atividades profissionais associadas a esses saberes tivessem maior participação masculina e a eles fossem agregados maior reconhecimento social.

Este trabalho apresenta uma reflexão sobre a divisão sexual do trabalho, analisando particularmente profissões consideradas da área científica e tecnológica, entre as quais Matemático(a), Físico(a), Químico(a), Estatístico(a), Engenheiro(a) e Professor(a) do Ensino Superior, buscando verificar avanços na participação das mulheres nessas atividades associadas historicamente ao masculino.

\section{PRESENÇA FEMININA NOS CURSOS SUPERIORES}

A ampliação do número de mulheres na educação superior tem contribuído para o avanço da presença feminina em diversas profissões antes consideradas como verdadeiros redutos masculinos. Vale destacar que a participação das mulheres nas áreas objeto de análise deste artigo - Engenharia, Matemática, Estatística, Física, Química ou Magistério Superior - pressupõe, em grande medida, a conclusão do respectivo curso superior, o que torna relevante compreender o universo educacional numa perspectiva de gênero.

Os indicadores educacionais do Brasil revelam que a maioria dos estudantes do 
ensino superior são mulheres. Considerando os dados referentes ao ano de 2005, verificase que a vantagem feminina - em termos quantitativos - ocorre entre discentes ingressantes, matriculados e concluintes de graduação presencial no país, conforme mostra tabela1:

Tabela 1: Participação de mulheres e homens no ensino superior presencial - Brasil 2005 (\%)

\begin{tabular}{|l|c|c|c|}
\hline & Feminino & Masculino & Total \\
\hline Ingresso & 55 & 45 & 100 \\
\hline Matrícula & 56 & 44 & 100 \\
\hline Conclusão & 62 & 38 & 100 \\
\hline
\end{tabular}

Fonte: Ristoff, 2007, com base em dados do MEC/Inep/Deas

Considerando que, segundo Ristoff (2007), a participação feminina entre os concluintes de 1991 era 59,9\% (141.678 mulheres) e que, em 2005, ampliou-se para $62,2 \%$ (446.724 mulheres), verifica-se que, em aproximadamente uma década e meia, ocorreu uma elevação do número de mulheres no ensino superior, tanto em termos relativos quanto absolutos, representando mais 305.046 mulheres concluintes de um curso superior presencial no país.

Em 2005 (tabela 1) podemos verificar que ocorre uma ampliação da participação feminina, quando comparados os números de ingresso, matrícula e conclusão. Se entre os ingressantes, as mulheres representam 55\%; entre os concluintes, esse percentual é de $62,2 \%$. Embora os dados de ingressantes e concluintes não se refiram ao mesmo universo de pessoas, pode-se conjecturar que, além de constituir a maioria no ensino superior, as mulheres também obtêm maior êxito nesse nível de ensino, concluindo um curso em uma proporção maior que a masculina.

Todavia, essa maior participação feminina não se reflete em todos os cursos, pois, as mulheres se concentram em determinados cursos, em geral da área de humanas, conforme mostra a tabela 2 :

Tabela 2: Matrículas - Brasil 2005

\begin{tabular}{l|c|c|c}
\hline \multicolumn{1}{c|}{ Curso } & $\begin{array}{c}\text { Feminino } \\
(\%)\end{array}$ & $\begin{array}{c}\text { Masculino } \\
(\%)\end{array}$ & $\begin{array}{c}\text { Total } \\
\text { (Absoluto) }\end{array}$ \\
\hline Administração & 49,2 & 50,8 & 671.660 \\
\hline Direito & 48,9 & 51,1 & 565.705 \\
\hline Pedagogia & 91,3 & 8,7 & 372.159 \\
\hline Engenharia & 20,3 & 79,7 & 266.163 \\
\hline Comunicação Social & 56,6 & 43,4 & 197.068 \\
\hline Letras & 80 & 20 & 196.068 \\
\hline Ciências Contábeis & 50,7 & 49,3 & 171.022 \\
\hline Educação Física & 43,1 & 56,9 & 159.484 \\
\hline Enfermagem & 82,9 & 17,1 & 153.359 \\
\hline Ciência da Computação & 18,8 & 81,2 & 110.927 \\
\hline Total & 55,9 & 44,1 & 4.453 .156 \\
\hline
\end{tabular}

Fonte: RISTOFF, 2007 - com base em dados do MEC/Inep/Deas, p. 10 
Podemos verificar uma distribuição de gênero desigual entre os cursos. Há uma nítida divisão sexual nos processos de formação, destacando-se a baixa participação feminina nos cursos de Engenharia e Ciência da Computação e a elevada presença das mulheres nos cursos de Pedagogia e Enfermagem. Dados que confirmam a permanência de uma presença masculina maior na área tecnológica - ainda percebida como campo masculino - e uma concentração feminina em áreas associadas ao cuidado (magistério e enfermagem) - socialmente vistas como áreas de atuação feminina.

Quando comparados esses números com os dados referentes ao ano de 2000 (RISTOFF, 2007), verificamos que a participação das mulheres na Engenharia tem uma ampliação tímida, pois, elas representavam 19,5\%, passando para 20,3\%, em 2005.

Para os cursos de maior participação feminina, percebemos uma ampliação masculina nos cursos de Pedagogia (os homens representavam 7,5\% em 2000 e passaram a representar 8,7\% em 2005) e no curso de Letras (17,5\% em 2000 e 20\% em 2005).

Quanto ao curso de Ciência da Computação, verificamos a continuidade de uma tendência de "masculinização", uma vez que em 2000 a participação masculina era de $73,5 \%$, e desde lá esse percentual se ampliou ano a ano, chegando, em 2005, a 81,2\%.

Tais dados parecem indicar que a distribuição de gênero no sistema educacional tem relação direta com a manutenção da tradicional divisão sexual do trabalho, na qual o trabalho feminino está associado ao cuidado, e o masculino, à racionalidade.

A educação formal, especificamente a educação para o trabalho, consiste em uma relevante fase da construção dessa divisão, mas não é a única. A família é outro importante espaço, pois nela ocorre o início do direcionamento da escolha profissional. Nos processos de socialização familiar, não é incomum que os brinquedos sejam diferentes para meninos e meninas - jogos eletrônicos e carrinhos para eles, bonecas e miniaturas de utensílios domésticos para elas - o que desde cedo contribui para estimular e interferir sobre a escolha profissional de homens e mulheres e naturalizar a tradicional divisão sexual do trabalho. Assim, a compreensão dessa divisão depende da análise de fatores extraprofissionais, entre os quais o processo de socialização das crianças, a divisão sexual do trabalho doméstico e principalmente das relações de poder estabelecidas entre homens e mulheres.

\section{MERCADO DE TRABALHO E AS MULHERES}

A constante ampliação da escolaridade feminina tem contribuído para o avanço das mulheres nos diversos campos profissionais, entretanto, esse fator não tem sido suficiente para a consolidação de um mercado de trabalho não sexista.

Por inúmeros fatores (profissionais e extraprofissionais), a presença feminina no mundo do trabalho continua marcada por processos que contribuem para a desvalorização de suas atividades - precarização (terceirização, informalidade, tempo parcial, baixos salários, flexibilidade no uso do trabalho, etc.) e segregação (pouca mobilidade na carreira e dificuldade para ascender aos postos hierarquicamente mais altos, concentração do trabalho feminino em determinados setores e funções).

Estatísticas sobre o trabalho demonstram a natureza da exclusão da mulher dentro e fora do mercado de trabalho, expressas em termos de segregação horizontal ocupacional e setorial - segregação vertical, trabalho desprotegido ou precário, remuneração mais baixa e mobilidade de carreira restrita. A exclusão das mulheres, 
segundo a autora, incorpora elementos estruturais de exclusão, bem como aqueles reproduzidos socialmente por meio de comportamentos, estereótipos de papéis de gênero e instituições. Neste sentido, as causas dessa exclusão são reproduzidas por meio de uma rede de relações que opera em diferentes níveis: individuais, sociais, políticos, econômicos e institucionais (Posthuma, 1998).

Dados da Relação Anual de Informações Sociais do Ministério do Trabalho e Emprego (RAIS) confirmam a significativa participação das mulheres no mercado formal de trabalho coexistindo com a manutenção da desigualdade de gênero nesse âmbito. Observamos que, em 2006, de um total de aproximadamente 50 milhões de empregos formais, cerca de $40 \%$ eram ocupados por mulheres. Todavia, os dados apontam que a taxa de participação feminina vai se reduzindo em faixas de salários mais elevados: se entre os trabalhadores que recebem até 0,5 salário mínimo, aproximadamente, $52 \%$ são mulheres, entre os que recebem mais de 20 salários mínimos, aproximadamente, 27\% deles são do sexo feminino.

Poderíamos supor que a ampliação da escolarização das mulheres acabaria com tais desigualdades, no entanto, a escolarização enquanto fator isolado não tem o poder de eliminar a discriminação da mulher no mercado de trabalho, uma vez que isso exigiria ações que possibilitassem a construção da igualdade material entre homens e mulheres, entre as quais políticas públicas de gênero em favor das mulheres, ações para desconstruir estereótipos de gênero e a cultura sexista, alterações na divisão sexual dos processos de formação e do trabalho produtivo e reprodutivo. Isso não retira, no entanto, a grande importância da escolarização para as mulheres, afinal, ela consiste em condição sine qua non para a entrada em determinadas profissões.

Outra questão que vale ser destacada refere-se aos conceitos de ciência e tecnologia que, socialmente construídos são frutos de relações de poder que classificam o que pode ser e o que não pode ser considerado como científico e tecnológico, assim como valorizam os conhecimentos e as atividades de forma desigual. É certo que inúmeros outros cursos e profissões poderiam ser considerados como científicos ou tecnológicos, todavia, muitas atividades desenvolvidas pelas mulheres não foram e não são assim consideradas.

Schiebinger (2001) nos lembra que, boa parte do que não tem sido contado como ciência tratava do lado privado da vida e era associado às mulheres. E que entre esses campos estão a economia doméstica, que lida com a administração e o projeto da vida familiar, e a enfermagem, que trabalha com o cuidado e o conforto diário de pacientes. Dessa forma, os conceitos de ciência e de tecnologia acabam não englobando muitas atividades femininas, o que influencia nos dados sobre a participação das mulheres nessa área.

Em relação às profissões científicas e tecnológicas, nem sempre se inclui entre elas os(as) docentes. A docência em instituições de ensino superior é uma profissão que deve ser destacada, uma vez que esses profissionais formam aqueles que atuarão nas áreas científicas e tecnológicas, além deles próprios desenvolverem atividades de pesquisa e de desenvolvimento, pois as suas atividades laborais pressupõem a indissociabilidade entre ensino, pesquisa e extensão. Destaca-se que o magistério em qualquer nível e modalidade de ensino - educação infantil, ensino fundamental, ensino médio, educação de jovens e adultos, educação profissional - deveria ser caracterizada como atividade essencial ao desenvolvimento científico e tecnológico, pois a construção do conhecimento não se inicia no ensino superior, mas faz parte de um processo que se 
inicia nos primeiros anos de vida e depende da valorização e reconhecimento do trabalho desses(as) profissionais.

Embora a carreira docente esteja bastante associada ao feminino, observamos que, quando se trata de professores do ensino superior, são os homens que compõe a maioria (tabela 3).

Tabela 3: Docentes do Ensino Superior: Brasil - 2001 e 2005

\begin{tabular}{c|c|c}
\hline Ano & Feminino & Masculino \\
\hline 2001 & $85.564(41,9 \%)$ & $118.542(58,1 \%)$ \\
\hline 2005 & $129.640(44,3 \%)$ & $162.864(55,7 \%)$ \\
\hline
\end{tabular}

Fonte: RISTOFF, 2007 - com base em dados do MEC/Inep/Deas, p. 10.

Destacamos, no entanto, que entre 2001 e 2005 ocorre um crescimento da participação das mulheres no magistério superior, assim como uma elevação no número de profissionais nessa área. Não obstante, a participação masculina permanece superior à feminina.

Para fins de análise, consideramos a Física, a Estatística e a Matemática associadas ao campo científico e, as Engenharias, ao tecnológico. Dessa forma, verificamos que as mulheres têm uma maior participação no campo científico do que no tecnológico (tabela 4). Destacamos o aumento da participação feminina no número de empregos de matemáticos (em 2006, os empregos das mulheres passam a representar mais de 44\% dos empregos) e uma estagnação na ampliação da presença feminina na área tecnológica- já bastante reduzida, particularmente, nas engenharias.

A tabela 4 revela ainda que, com exceção da Estatística e Arquitetura, em todas as demais carreiras analisadas, o número de empregos masculinos é sempre superior aos femininos. A Engenharia Mecânica é a que apresenta a menor participação feminina, mantendo uma tradição histórica de campo de trabalho majoritariamente masculino.

Os dados apontam ainda que, além da participação das mulheres na Engenharia não ter sofrido uma alteração significativa entre os anos de 2001 e 2006, manteve-se uma distribuição de gênero bastante desigual: a presença masculina, tanto em 2001 quanto em 2006, era superior a $80 \%$, o que a configura a Engenharia no Brasil como um universo predominantemente masculino.

Em 2006, ao desagregar os dados de Engenharia Civil e Arquitetura que em 2001 foram tabulados em conjunto, verificamos que a participação feminina nas duas áreas, que era 22\% (em 2001), passou, em 2006, para aproximadamente 17\% em Engenharia Civil e 55\% em Arquitetura. Números que apontam para uma continuidade da caracterização da Engenharia Civil como campo de atuação profissional predominantemente masculino e a Arquitetura como campo de atuação profissional com distribuição de gênero mais equitativa e com uma pequena vantagem numérica para as mulheres. 
Tabela 4: Distribuição, por gênero, do número de empregos em carreiras científicas e tecnológicas: Brasil 2001 e 2006 (\%)

\begin{tabular}{l|c|c|c|c}
\hline \multirow{2}{*}{ Profissões } & \multicolumn{2}{|c|}{2001} & \multicolumn{2}{c}{2006} \\
\cline { 2 - 5 } & Feminino & Masculino & Feminino & Masculino \\
\hline Químico & 45 & 55 & 43 & 57 \\
\hline Físico & 38 & 62 & 34 & 66 \\
\hline Estatístico & 51 & 49 & 56 & 44 \\
\hline Matemático & 37 & 63 & 44 & 56 \\
\hline Engenheiro Civil & & & & \\
e Arquiteto & 22 & 78 & - & - \\
\hline Arquiteto & - & - & 55 & 45 \\
\hline Engenheiro Civil e afins & - & - & 17 & 83 \\
\hline Engenheiro Eletricista e & & & & \\
Engenheiro Eletrônico & 10,2 & 89,8 & 9,7 & 90,3 \\
\hline Engenheiro Mecânico & 5,2 & 94,8 & 5,6 & 94,4 \\
\hline
\end{tabular}

Fonte: elaboração própria, com base em dados da Rais 2001 e 2006.

No que se refere aos salários (tabela 5), verificamos que, em 2006, as mulheres, de forma geral nas profissões analisadas, permanecem com salários inferiores aos masculinos, pois, em termos relativos, sempre um número maior de mulheres do que de homens recebe salários na menor faixa salarial - até 10 salários mínimos.

Verificamos ainda que a maior concentração dos profissionais nessa menor faixa é no Magistério Superior. Embora um número significativo de empregos masculinos (71\%) tenha salários de até 10 salários mínimos, proporcionalmente tem-se um maior número de mulheres concentradas nessa faixa $-85 \%$

Mesmo entre os matemáticos e estatísticos - profissões que apresentam uma distribuição mais eqüitativa de gênero, com participação feminina de $44 \%$ e $56 \%$, respectivamente, ou aproximadamente $49 \%$ quando considerados em conjunto - a distribuição salarial permanece desigual, com um número maior de homens nas faixas salariais superiores, conforme se observa na tabela 5.

Tabela 5: Participação de homens e mulheres nas faixas salariais de profissionais científicos e tecnológicos: Brasil - 2006 (\%)

\begin{tabular}{l|c|c|c|c}
\hline \multirow{2}{*}{ Profissão } & \multicolumn{4}{|c}{ Salários } \\
\cline { 2 - 5 } & \multicolumn{2}{|c}{ até 10 sm } & \multicolumn{2}{c}{ superiores a 10 sm } \\
\cline { 2 - 5 } & Mulheres & Homens & Mulheres & Homens \\
\hline Matemáticos, estatísticos e afins & 60 & 44 & 40 & 56 \\
\hline Físicos, químicos e afins & 54 & 36 & 46 & 64 \\
\hline Engenheiros, arquitetos e afins & 51 & 35 & 49 & 65 \\
\hline Professores do ensino superior & 85 & 71 & 15 & 29 \\
\hline
\end{tabular}

Fonte: elaboração própria, com base em dados da Rais 2006. 
No que se refere à idade dos profissionais, a tabela 6 apresenta uma distribuição em duas faixas etárias: "igual ou inferior a 39 anos" ou "igual ou superior a 40 anos". Pode-se verificar que as mulheres apresentam um perfil mais jovem que o apresentado pelos homens, concentrando-se na faixa etária "igual ou inferior a 39 anos". Apenas quando consideramos as professoras do ensino superior é que temos a maioria delas com idade acima dessa faixa. Já entre os homens, podemos observar que eles se apresentam, em grande medida, com idade "igual ou superior a 40 anos", com exceção dos matemáticos e estatísticos.

\section{Tabela 6: Participação de homens e mulheres nas faixas etárias de profissionais científicos e tecnológicos: Brasil 2006 (\%)}

\begin{tabular}{l|c|c|c|c}
\hline \multirow{2}{*}{ Profissão } & \multicolumn{4}{|c}{ Igual ou } \\
\cline { 2 - 5 } & \multicolumn{2}{|c}{ inferior a 39 anos } & \multicolumn{2}{c}{ superior a 40 anos } \\
\cline { 2 - 5 } & Mulheres & Homens & Mulheres & Homens \\
\hline Matemáticos, estatísticos e afins & 57 & 61 & 43 & 39 \\
\hline Físicos, químicos e afins & 63 & 44 & 37 & 66 \\
\hline Engenheiros, arquitetos e afins & 64 & 50 & 36 & 50 \\
\hline Professores do ensino superior & 41 & 44 & 59 & 56 \\
\hline
\end{tabular}

Fonte: elaboração própria, com base em dados da Rais 2006.

A maioria dos empregos femininos na engenharia ou arquitetura (64\%) tem mulheres com idade "igual ou inferior a 39 anos". Já entre os homens, metade deles está na faixa de idade superior a 40 anos e metade na faixa abaixo dos 40 anos. Esses dados podem ser indício de que está ocorrendo uma entrada maior de jovens engenheiras e arquitetas no mercado de trabalho em relação ao que ocorria há algumas décadas.

\section{CONSIDERAÇÕES FINAIS}

A divisão sexual do trabalho, ao hierarquizar e atribuir maior valor às atividades "masculinas" contribui para a desvalorização do trabalho não só das mulheres, mas de todos e todas que optam por profissões socialmente associadas ao feminino. É possível questionar se uma profissão ao se feminizar se desvaloriza ou se a desvalorização de uma determinada profissão poderia ter alguma associação com a sua possível feminização. Considerando que, embora exista indícios de uma possível relação entre desvalorização e feminização, consideramos que essa relação não é diretamente proporcional e que, além do mais, a divisão sexual do trabalho envolve relações de poder e, por ser historicamente e socialmente construída pode também ser reconstruída a partir de novos valores. Nessa reconstrução, parece relevante inicialmente questionar "para quê" e "para quem" serve a desvalorização das atividades femininas?

A desconstrução de uma divisão sexual do trabalho, tanto no que se refere à separação fixa e imutável de atividades masculinas e femininas, quanto no que se refere a diferente valorização dessas atividades pode contribuir para a construção da equidade 
de gênero e valorização das atividades de homens e mulheres.

Neste sentido, o estímulo para que mulheres ingressem em profissões consideradas masculinas e para que homens ingressem em profissões consideradas femininas é um desafio necessário para a derrubada de muros invisíveis, tetos de cristais, paredes de vidro e inúmeras barreiras que, embora, não sejam vistas, inviabilizam a construção da equidade de gênero no mundo do trabalho.

Citelli (2005) apresenta uma reflexão que ajuda na reflexão sobre a importância das mulheres na ciência e tecnologia, pois, ao contrário do que se pode sugerir, a polêmica não reside na injustiça contra as mulheres e, menos ainda, no direito que estas têm à prática científica. A principal questão se concentra nos benefícios que a incorporação das mulheres pode trazer à ciência e tecnologia, pois, a baixa representação feminina ameaça esses conhecimentos, sobretudo, pela perda de talentos e de genialidade da metade da população. Não há dúvida de que as mulheres têm o direito ao acesso e permanência em qualquer profissão, mas devemos considerar que a efetivação desse direito no âmbito das profissões científicas e tecnológicas ainda depende de vários fatores, entre os quais a desconstrução da idéia de que a ciência e da tecnologia sejam campos associados ao masculino. Uma maior participação feminina nessas áreas beneficiaria o desenvolvimento cientifico e tecnológico do país e poderia contribuir para que esse desenvolvimento se revertesse em outros, particularmente o social.

A partir das reflexões apresentadas neste texto, verifica-se que a temática "gênero, ciência e tecnologia" permanece um campo com muitas possibilidades de pesquisa. Detectar e compreender os obstáculos para a entrada das mulheres nas carreiras científicas e tecnológicas e o que deve ser feito para eliminá-los, continua sendo um desafio. Tal questão exige empenho no sentido de encontrar respostas que possam contribuir para a construção de uma sociedade justa, na qual homens e mulheres possam desenvolver plenamente suas potencialidades e que suas escolhas profissionais não sejam inviabilizadas por barreiras de gênero.

\section{REFERÊNCIAS}

CITELLI, Maria Teresa. Laboratório de preconceitos. In: Jornal da Ciência: JC e-mail 2698, 31 de jan. de 2005.

LOMBARDI, Maria Rosa. Perseverança e resistência: a engenharia como profissão feminina. Tese de doutorado. UNICAMP, 2005.

POSTHUMA, Anne Caroline. Mercado de trabalho e exclusão social da força de trabalho feminina. In ABRAMO, Laís; ABREU, Alice Rangel de Paiva (orgs.). Gênero e trabalho na sociologia latino-americana. São Paulo; Rio de Janeiro: ALAST, 1998. p. 21- 38.

RISTOFF, Dilvo et al (orgs.)A mulher na educação superior brasileira: 1991-2005.

SCHIEBINGER, Londa. O feminismo mudou a ciência? SP: EDUSC, 2001. 